\title{
EARLY DETECTION OF FACTORS, INCLUDING Pandemics ANd Disasters, Leading To LANGUAGE ENDANGERMENT: THINKING STATISTICALLY
}

\author{
Deepak Sharma \\ Department of Information Technology \\ Institute of innovation, Technology and Management \\ Affiliated to Guru Gobind Singh Indraprastha University, Dwarka, Delhi-110078, India
}

\begin{abstract}
The target of this research work is to use a statistical technique on different languages to identify significant factors of endangered languages with similar characteristics to build a model for language endangerment. Factor analysis is used to identify factors. The factors are used to construct a model with and without interaction terms. First three variables (i.e. speakers, longitude and latitude) are analyzed to identify two factors and then these three variables and three interaction terms are used to construct the model. Different variables were identified and a model with and without interaction terms is built using the identified factors. The result shows that the model has significant predictive power. The predictors were retrieved from the dataset. The outcome encourages future studies towards defining techniques of language endangerment prediction for analyzing factors of language endangerment.
\end{abstract}

Key words: Computational Intelligence, Language Endangerment, Computing, Testing

\section{INTRODUCTION}

Statistical modeling for language endangerment is a process, which intends to find the dialect to complete tractability and strength in endangered languages (Trudgill, 2008). This paper presents a comprehensive view of modeling techniques based on computational intelligence and statistical test to find out if language endangerment problem is presented. An endangered language is a dialect that is at danger of dropping out of utilization as its speakers move to talking another language (Axelrod, 2006). It happens when the language has no more local speakers and the language becomes a "dead language". If nobody uses the language it turns into a "wiped out language phase" by (Austin and Sallabank, 2011). Despite the fact that dialects have dependably turned out to be wiped out all through mankind's history, they are as of now vanishing at a very fast pace due to globalization and neocolonialism, and the financially capable dialects command different dialects (Paraschakis, 2013). In this research, we try to elaborate some problems like how to model computation and statistics in language endangerment and their solutions, which are based on artificial intelligence (Hamari, 2014) and (Benjamin, 2014). The paper presents an overview of the usage of computational modeling and artificial intelligence techniques in language endangerment (henceforth LE).

\section{Experimental Design and Method}

The term Factor Analysis (FA) is a data reduction technique consisting of set of procedures or mechanisms which are used to reduce the many variable data into fewer variables, also termed factors (Johnson and Wichern 2002; Hair et al. 2010; Lawley and Maxwell 1973; Basilevsky, 1981). The method of factorization takes place according to the relevance of characteristics among predictors.

\section{Proposed model}

The proposed model is designed to identify the influential factors for the language endangerment (LE) problem. The model consists of different phases in order to identify the significant factors for the problem. Figure 1 describes the phases of model testing for LE.

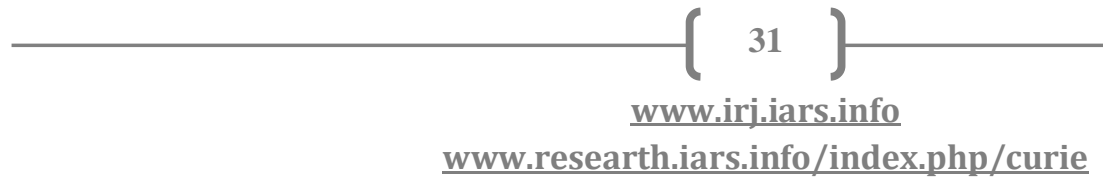




\section{Yimternational Research Journal}

p-ISSN 2202-2821 e-ISSN 1839-6518 (Australian ISSN Agency)

\section{Results and Discussions}

The results clearly indicate that the factor variables are far better than the normal predictors. In the case of a superset of interaction terms the results are significant as compared to the other results. The main finding is that in the case of the interaction module values of total variance is good with superset of 6 factor variables as compared to the values of superset of 3 terms. Therefore, we conclude that after the reduction of variables, the values of total variance is also significant. Factor analysis is therefore a good technique for LE problems. In this research, we perform an analysis with review of past studies to check and assess the performance of the Factor analysis statistical technique for LE.

\section{A. Experiment 1}

First, a rigorous study is done by following a systematic review, and a few studies (see Austin, 2011; Benjamin, 2014). Secondly, the dataset (Johnson and Wichern, 2002), (Hair et al. 2010), (Lawley, 1973), (Basilevsky, 1981) and (Kaggle, 2016) considered for this study and checked by using the Kaiser Meyer Olkin (KMO) and Bartlett's Test (measures the strength of relationship among the variables) is presented in Table 1 with its measures from Tables 2-6 in experiment 1 with Figure 2 and from Tables 7-12 in experiment number 2 with Figure 3 for the applicability of factor analysis. After investigating this we applied it on the dataset. The significant variables for LE are predicted by factor analysis.

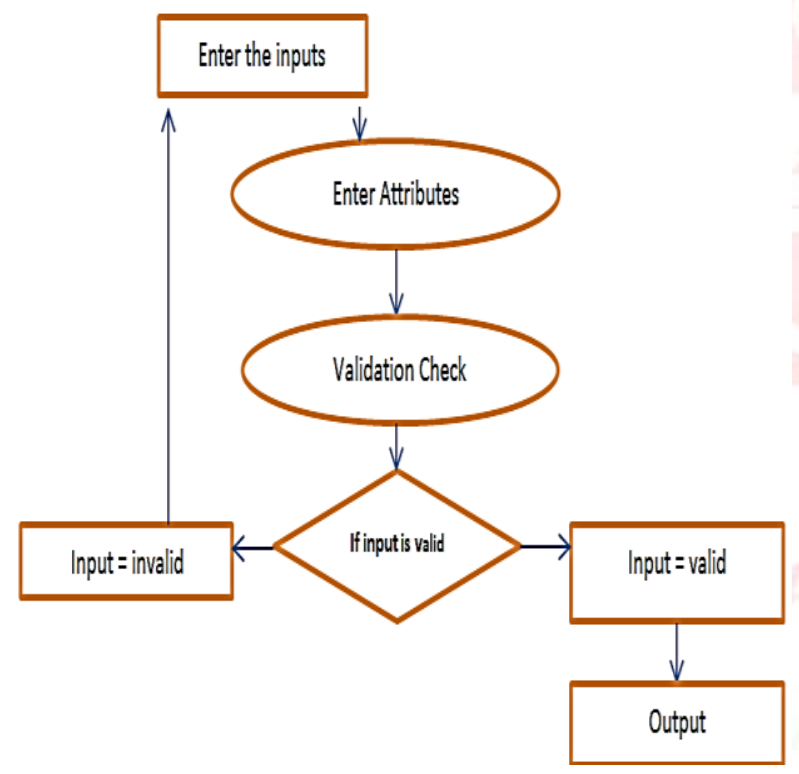

Figure 1: describes the phases of model testing for LE

Then, we compare the Total variance (Table 3 ) which shows the variance explained by each factor and the rotated factor matrix indicates the group of variables. Finally, we summarized the main findings obtained from the results predicted in tabular form.

\begin{tabular}{|l|l|r|}
\hline \multicolumn{3}{|c|}{ Table 1 KMO and Bartlett's Test } \\
\hline Kaiser-Meyer-Olkin Measure of Sampling Adequacy. \\
\hline \multirow{3}{*}{ Bartlett's Test of Sphericity } & Approx. Chi-Square & 168.635 \\
\cline { 2 - 3 } & Df & 3 \\
\cline { 2 - 3 } & Sig. & .000 \\
\hline
\end{tabular}

\begin{tabular}{|c|c|c|}
\hline \multicolumn{3}{|c|}{ Table 2 Communalities } \\
\hline & Initial & Extraction \\
\hline Latitude & 1.000 & .634 \\
\hline Longitude & 1.000 & .729 \\
\hline Speakers & 1.000 & .894 \\
\hline
\end{tabular}

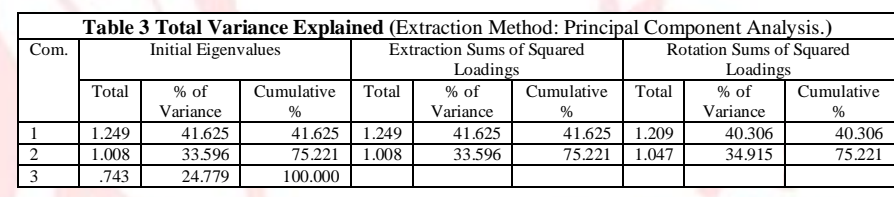

The factor analysis has admissible prediction competence for judging LE. The cumulative percentage in total variance explained in experiment 1 is 75.221 and in experiment 2 is 65.564, which are good.

\begin{tabular}{|l|c|c|}
\hline \multicolumn{3}{|c|}{ Table 4 Component Matrix ${ }^{\mathbf{a}}$} \\
\hline & \multicolumn{2}{c|}{ Component } \\
\cline { 2 - 3 } & 1 & 2 \\
\hline Latitude & .796 & \\
\hline Longitude & -.678 & \\
\hline Speakers & & \\
\hline
\end{tabular}

Extraction Method: Principal Component Analysis.

a. 2 components extracted.

\begin{tabular}{|c|c|c|c|}
\hline \multicolumn{4}{|c|}{ Table 5 Rotated Component Matrix ${ }^{a}$} \\
\hline & \multicolumn{3}{|c|}{ Component } \\
\hline & 1 & \multicolumn{2}{|l|}{$\frac{n t}{2}$} \\
\hline Latitude & -.721 & & \\
\hline Longitude & .830 & & \\
\hline Speakers & & & .945 \\
\hline \multicolumn{4}{|c|}{$\begin{array}{l}\text { Extraction Method: Principal Component Analysis. } \\
\text { Rotation Method: Varimax with Kaiser Normalization. }\end{array}$} \\
\hline \multicolumn{4}{|c|}{ a. Rotation converged in 3 iterations. } \\
\hline \multicolumn{4}{|c|}{$\begin{array}{r}\text { Table } 6 \text { Component Transformation Matrix } \\
\end{array}$} \\
\hline Component & & 1 & 2 \\
\hline 1 & & -.914 & .405 \\
\hline 2 & & .405 & .914 \\
\hline
\end{tabular}




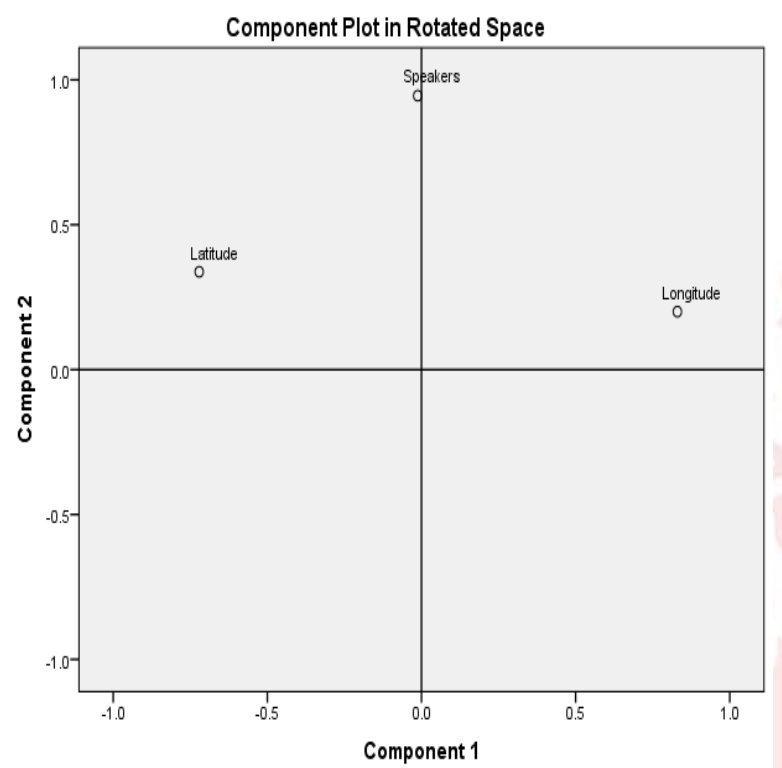

\begin{tabular}{|c|c|c|}
\hline \multicolumn{3}{|c|}{\begin{tabular}{c|c} 
Table 10 Component Matrix \\
\end{tabular}} \\
\hline & Comp & 2 \\
\hline \multicolumn{3}{|l|}{ Latitude } \\
\hline Longitude & & .867 \\
\hline Speakers & .922 & \\
\hline $\mathrm{A}$ & & .759 \\
\hline $\mathrm{B}$ & .936 & \\
\hline $\mathrm{C}$ & .760 & \\
\hline \multicolumn{3}{|c|}{ Extraction Method: Principal Component Analysis. } \\
\hline \multicolumn{3}{|c|}{2 components extracted. } \\
\hline \multicolumn{3}{|c|}{ Table 11 Rotated Component Matrix ${ }^{a}$} \\
\hline & \multicolumn{2}{|c|}{ Component } \\
\hline & 1 & 2 \\
\hline \multicolumn{3}{|l|}{ Latitude } \\
\hline Longitude & & .874 \\
\hline Speakers & 928 & \\
\hline A & & .774 \\
\hline B & .943 & \\
\hline $\mathrm{C}$ & .752 & \\
\hline
\end{tabular}

Figure 2: Scree plot of the eigenvalues of factors i.e. Latitude, Longitude and Speakers

\section{B. Experiment 2}

Table 7 KMO and Bartlett's Test

\begin{tabular}{|l|l|r|}
\hline \multicolumn{2}{|c|}{ Kaiser-Meyer-Olkin Measure of Sampling Adequacy. } & .599 \\
\hline \multirow{3}{*}{ Bartlett's Test of Sphericity } & \multicolumn{1}{|c|}{ Approx. Chi-Square } & 6745.133 \\
\cline { 2 - 3 } & Df & 15 \\
\cline { 2 - 3 } & Sig. & .000 \\
\hline
\end{tabular}

Table 12 Component Transformation Matrix

\begin{tabular}{|l|r|r|}
\hline Component & 1 & \multicolumn{1}{|c|}{2} \\
\hline 1 & .996 & .084 \\
\hline 2 & -.084 & .996 \\
\hline
\end{tabular}

Extraction Method: Principal Component Analysis.

Rotation Method: Varimax with Kaiser Normalization.

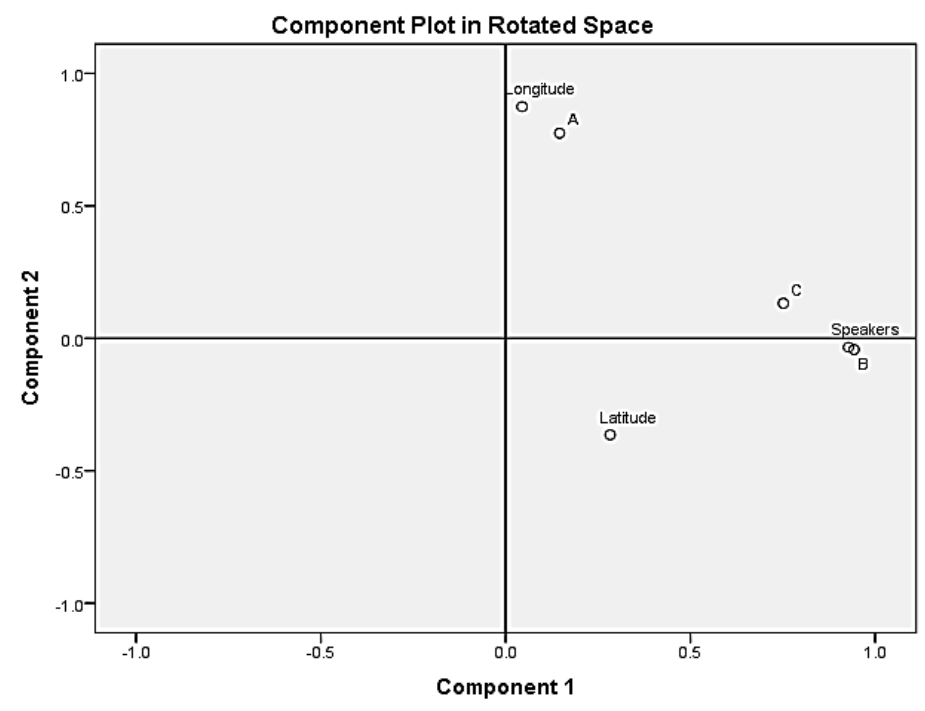

Figure 3: Scree plot of the eigen values of factors i.e. Latitude, Longitude and Speakers with their interactions 


\section{Conclusion}

This article presents an empirical validation of statistical approaches for LE problem. By using such approaches for LE, we tried to search for the major important factors related to the LE problem. It includes a conceptual discussion of all such methodologies, looking at different criteria of classification and earlier efforts to develop categories for effective and efficient testing for building models of LE. This study has been the basis to develop a proposal for a new anatomy, which is a helpful conceptual tool to both understand and organize the existing work, and to identify possible areas for future research. The study also includes an exhaustive review of the literature in the area, starting from the pioneering works in statistical techniques with testing techniques for LE. The main characteristics of the techniques engaged, as well as the application problems, future directions and results obtained, are presented and can be a source of inspiration for future research in the field.

\section{REFERENCES}

[1]. Austin, P. K., \& Sallabank, J. (Eds.) The Cambridge handbook of endangered languages. Cambridge University Press. (2011).

[2]. Axelrod, Robert. Agent-based modeling as a bridge between disciplines. In Leigh Tesfatsion, Kenneth L. Judd (eds.), Handbook of Computational Economics Vol. 2: Agent-Based Computational Economics, 1565-1584. Amsterdam: North Holland/Elsevier. (2006).

[3]. Basilevsky, A. Factor analysis regression. Canadian Journal of Statistics, 9(1), 109-117. (1981).

[4]. Benjamin, M., \& Radetzky, P. Multilingual lexicography with a focus on less-resourced languages: Data mining, expert input, crowdsourcing, and gamification. In 9th edition of the Language Resources and Evaluation Conference (No. CONF). (2014).

[5]. “Extinct Languages", Kaggle.com, [Online]. Available: https://www.kaggle.com/theguardian/extinct-languages. (2010).

[6]. Hair, J. F., Anderson, R. E., Babin, B. J., \& Black, W. C. Multivariate data analysis: A global perspective. (vol. 7). Pearson Upper Saddle River, New Jersey, Pearson. (2010).

[7]. Hamari, J., Koivisto, J., \& Sarsa, H. Does gamification work?--a literature review of empirical studies on gamification. In 2014 47th Hawaii international conference on system sciences (pp. 3025-3034). IEEE. 2014
[8]. Johnson, R. A., \& Wichern, D. W. Applied multivariate statistical analysis (Vol. 5, No. 8). Upper Saddle River, NJ: Prentice hall. (2002).

[9]. Lawley, D. N., \& Maxwell, A. E. Regression ana factor analysis. Biometrika, 60(2), 331-338. (1973). Online available (https://ieeexplore.ieee.org/abstract/document/675897 8). (2014, January).

[10]. Paraschakis, D. Crowd sourcing cultural heritage metadata through social media gaming. Online available (https://muep.mau.se/handle/2043/16114). (2013).

[11]. Trudgill, P. On the role of children, and the mechanical view: A rejoinder. Language in Society, 37(2), 277-280. (2008). 


\section{Manuscript Processing Footprints}

\section{A. Journal Volume/Issue Details}

This manuscript it published in Vol. 11 No. 012021 issue of IARS' International Research Journal (I'IRJ) This is a Peer Reviewed (Refereed) International Journal archived with National Library of Australia. The mentioned Volume/Issue is a special issue of the journal dedicated to Covid19 Pandemic Conditions across globe.

\section{B. Citation}

Sharma, Deepak (2021) "EARLY DETECTION OF FACTORS, INCLUDING PANDEMICS AND DISASTERS, LEADING TO LANGUAGE ENDANGERMENT: THINKING STATISTICALLY”, IARS' International Research Journal. Vic. Australia, 11(1). Available at: https://researth.iars.info/index.php/curie

\section{Author Declaration}

- The submission has not been previously published, nor is it before another journal for consideration (or an explanation has been provided in Comments to the Editor).

- The submission file is in OpenOffice, Microsoft Word, or RTF document file format.

- Where available, URLs for the references have been provided.

- The text is single-spaced; uses a 12-point font; employs italics, rather than underlining (except with URL addresses); and all illustrations, figures, and tables are placed within the text at the appropriate points, rather than at the end.

- The text adheres to the stylistic and bibliographic requirements outlined in the Author Guidelines.

- All Terms and Conditions about submission and publishing with IARS' International Research Journal on its official site and other sources have been gone through, understood, and accepted.

- With submission, this is declared that the submitter has all rights of the content, and to submit it. Also the submitter affirms that the rights of the submitted content are hereby transferred to IARS' international Research Journal and its parent company/publisher, without objections or conditions.

\section{Last Plagiarism Report}

Settings : similarity of 09 words in a row considered plagiarized.

Originality Assessment

\section{Overall Similarity: $3 \%$}

Date: Jan 11, 2021

Statistics: 49 words Plagiarized / 1627 Total words

Remarks: Low similarity detected, check your supervisor if changes are required. Sources

\begin{tabular}{|c|c|}
\hline 1 & $\begin{array}{l}\text { http://shodhganga.inflibnet.ac.in/bitstream/10603/12350/15/15_chapter\%205.pdf } \\
\text { INTERNET } \\
1 \%\end{array}$ \\
\hline 2 & $\begin{array}{l}\text { https://www.ncbi.nlm.nih.gov/pmc/articles/PMC6387509/ } \\
\text { INTERNET } \\
1 \%\end{array}$ \\
\hline 3 & $\begin{array}{l}\text { http://www2.econ.iastate.edu/tesfatsi/aintro.htm } \\
\text { INTERNET } \\
1 \%\end{array}$ \\
\hline
\end{tabular}

Exemption / Relaxation by Editor: None

\section{E. Processing Track}

\begin{tabular}{|l|l|}
\hline Date of Submission: & 08 November 2020 \\
\hline Date of Referee/Review - 1: & 01 December 2020 \\
\hline Date of Referee/Review - 2: & 03 January 2021 \\
\hline Date of Additional Review: & NA \\
\hline Date of Acceptance: & 11 January 2021 \\
\hline Date of Publishing: & 08 February 2021 \\
\hline
\end{tabular}

